\title{
Review: acellular vaccines prevent pertussis as effectively as whole-cell vaccines with fewer adverse events
}

Tinnion ON. Acellular vaccines for preventing whooping cough in children. Cochrane Review, latest version 24 Feb 1999. In: Cochrane Library. Oxford: Update Software.

QUESTION: In children $\leqslant 6$ years of age, how well do acellular vaccines (compared with whole-cell vaccines) protect against pertussis disease (whooping cough)?

\section{Data sources}

Studies were identified using Medline (1966-97) and the Cochrane Controlled Trials Register.

\section{Study selection}

Studies were selected if they were randomised, doubleblind, controlled trials of the efficacy or safety of acellular pertussis vaccines. Efficacy studies had to have active follow-up of participants and laboratory confirmation of pertussis.

\section{Data extraction}

Data were extracted on study quality, case definition (whooping cough or pertussis disease), immunisation schedule and vaccine characteristics, efficacy results (absolute or relative efficacy), and adverse events.

\section{Main results}

45 studies were included; all 45 addressed safety, and 6 studies addressed efficacy. 4 efficacy trials included placebo or diphtheria toxoid (DT) as the control therapy and thus permitted calculation of absolute efficacy: Acellular vaccines were more efficacious than placebo or DT in preventing whooping cough (absolute efficacy range $36 \%$ to $85 \%$ ); 3 of the 4 trials showed greater efficacy of acellular vaccines in preventing pertussis disease (absolute efficacy range $23 \%$ to $78 \%$ ). Acellular vaccines with $\geq 3$ components were more efficacious than vaccines with 1-2 components. 4 trials directly compared acellular vaccines with whole-cell vaccines. The acellular vaccines were relatively more efficacious than 1 type of whole-cell vaccine but less efficacious than 2 other types of whole-cell vaccine in preventing whooping cough. For most safety outcomes, including death from all causes and death from infection, acellular vaccine and whole-cell vaccines did not differ. 8 of 9 minor adverse events-anorexia, fever, irritability, prolonged crying, vomiting, pain or tenderness, redness, and swelling or induration-were reduced with acellular vaccines; drowsiness was not reduced. Non-completion of the primary series because of adverse effects was reduced in recipients of acellular vaccines (table).

\section{Conclusion}

Acellular pertussis vaccines are efficacious in preventing pertussis disease (whooping cough) in children $\leqslant 6$ years of age and are associated with fewer adverse events than whole-cell vaccines.

\section{COMMENTARY}

Acellular pertussis vaccines were developed because of concerns about adverse effects of whole-cell pertussis vaccines The review by Tinnion addresses clinically important questions relating to the efficacy (protection against pertussis disease in vaccinated people) and safety of these vaccines. It does not address vaccine effectiveness (effect on levels of disease in the community when the vaccine is introduced), which is affected by other factors, including vaccine uptake rates and herd immunity.

Assessing acellular vaccine efficacy has been complicated by substantial differences among acellular vaccines (those using $\geq 3$ pertussis components seem to be more efficacious than those with 1-2 components) and whole-cell vaccines. These differences, combined with schedule variations, precluded a meta-analysis of the efficacy trials. The best acellular vaccines approach the efficacy of the best whole-cell vaccines.

Safety is easier to address for common adverse events. To prevent 1 additional fever of $38^{\circ} \mathrm{C}$ from a whole-cell vaccine, the number needed to treat (vaccinate) with acellular vaccines is 4. For convulsions and hypotonichyporesponsive episodes, the relative reduction with acellular vaccines is statistically significant. The absolute difference is small, however, because of the rarity of these events, with differences of only 6 per 10000 primary courses both for convulsions and for hypotonic or hyporesponsive episodes.

National choice of vaccine type will be influenced by local rates of disease and death from pertussis, schedule timing, vaccine uptake rates, public acceptance of adverse events, and available funds. In developing countries, where the incidence of pertussis is high, acellular vaccines at a cost $>$ US $\$ 10$ per dose are probably a less viable option than improving coverage with whole-cell vaccines, which cost only a few cents per dose.

Jim Buttery, MBBS John Radcliffe Hospital Oxford, $U K$

1 Greco D, Salmaso S, Mastrantonio P, et al. A controlled trial of two acellular vaccines and one whole-cell vaccine against pertussis. Progetto Pertosse Working Group. $N$ Engl J Med 1996;334:341-8.
Source of funding: no external funding.

For correspondence: Dr O Tinnion, Master of Population Health Program, National Centre for

Epidemiology and Population Health, Australian National University, Canberra, Australian Capital Territory 0200, Australia. FAX +61-2-6249-0740.

Acellular vaccines $v$ whole-cell vaccines for preventing whooping cough (follow-up range $1 \mathrm{~d}$ to $28 \mathrm{mo}$ )*

\begin{tabular}{|c|c|c|c|c|c|}
\hline \multirow[b]{2}{*}{ Outcome } & \multirow{2}{*}{$\begin{array}{l}\text { Number } \\
\text { of } \\
\text { studies }\end{array}$} & \multicolumn{2}{|c|}{$\begin{array}{l}\text { Weighted event } \\
\text { rates }\end{array}$} & \multirow[b]{2}{*}{$\begin{array}{l}\text { RRR } \\
(95 \% \mathrm{CI})\end{array}$} & \multirow[b]{2}{*}{ NNT (Cl) } \\
\hline & & Acellular & $\begin{array}{l}\text { Whole } \\
\text { cell }\end{array}$ & & \\
\hline $\begin{array}{l}\text { Non-completion of } \\
\text { primary series }\end{array}$ & 14 & $0.37 \%$ & $1.17 \%$ & $\begin{array}{l}72 \% \\
(67 \text { to } 76)\end{array}$ & $\begin{array}{l}125 \\
\text { (111 to } 143)\end{array}$ \\
\hline
\end{tabular}

*Abbreviations defined in glossary; RRR, NNT, and Cl calculated from data in article. 